\title{
Helen Salisbury: Practising in the dark
}

\author{
Helen Salisbury GP \\ Oxford
}

I am missing my patients. The practice has moved from seeing nearly everyone, face to face, to doing mostly telephone consultations. Sometimes we switch to video halfway through if this will help us make a diagnosis.

After careful screening to exclude coronavirus symptoms we invite some patients into the practice to be examined. When they arrive at the surgery they are buzzed in at the back door and handed a mask. I'm also wearing a mask and a visor, which makes communication more difficult: I normally learn a lot from people's facial expressions, and it's hard to gauge their degree of discomfort, concern, or bafflement when I can't see the bottom half of their face. I habitually convey my interest and empathy with smiles and grimaces, but these now proceed unseen behind my mask.

These face-to-face consultations risk becoming transactional. I do the necessary examination and discuss the findings and management, but it feels disjointed. With longstanding patients I hope that this will be just a brief interruption to our normal relationship, but when I haven't previously met the patient it poses a significant challenge to building a rapport. My previous reservations about video consulting are now turned on their head because verbal and non-verbal communication by video link, while clearly missing some nuances, is now easier than in-person conversation through masks.

In the past week the number of new patients reporting coronavirus symptoms has fallen, as has the death rate at our local hospital. We're slowly relaxing our lockdown—seeing more patients and doing more in the way of investigations and preventive care. During a crisis it's relatively easy to decide what's immediately necessary: if the condition isn't life threatening it can wait until the emergency is over. But we cannot keep postponing care indefinitely, and the backlog of demand is growing. Some minor problems will resolve without intervention, but some serious conditions will sadly be missed. Our hospital is still accepting only emergency referrals as it too struggles to re-establish routine with the constraints of safe distancing, and frustration is rising in patients and doctors. We're making fine judgments each day, balancing for each patient the benefits of blood tests, cervical smears, or diabetes monitoring against the risk of coming to the surgery. It would be really useful to know the local prevalence of infection to inform these calculations, but at the moment we're in the dark. We know that there are cases in our city, some self-treating and some needing input from GPs or NHS 111—but, without access to testing or test results, we don't know who, where, or how many. If (or when) the expected second wave arrives we'll have to adapt again, and we'll need timely information to keep our patients and colleagues safe.

Competing interests: See www.bmj.com/about-bmj/freelance-contributors. Provenance and peer review: Commissioned; not externally peer reviewed.

Published by the BMJ Publishing Group Limited. For permission to use (where not already granted under a licence) please go to http://group.bmj.com/group/rights-licensing/ permissions 